\title{
Analysis on the Social Support of the Special Education Management Model and the Path
}

\author{
Yanfei Ren ${ }^{1, a}$ \\ ${ }^{1}$ Institute of Education Chifeng University ,024000,China \\ aemail:dbrenyanfei@126.com
}

Keywords: Special education; Management mode; Social support; Path

\begin{abstract}
Social work and the special education have traced the basis of values and ideas, and bring out the best in each other. Emphasizes humanist, helping social work values, thought that children have the right to obtain special needed resources, emphasizes from the angle of ecological system to set up a assessment and intervention of interactive services framework, in order to meet their needs and motivate them to achieve harmony with the environment. This kind of "people-oriented" and "ecosystem view" perspective with special education stick to fusion education concept of inclusive education emphasize the construction of a barrier-free inclusive society and promote the healthy development of special children. This article mainly elaborated our country special educational system in the expansion of social work support services, which need to further improve special-education policies, promote the professional integration, expand the practice pattern, and strengthen social propaganda.
\end{abstract}

\section{Introduction}

Hundred years' policy based on education; while the education policy based on teachers. Special education teachers shoulder the promote the full development; promote social fairness and justice of important responsibilities. Support special education, special education teachers should contain the core elements. For special education teachers' attention in the past, it is mainly focusing on how to build professional teachers, the social demand for special education teachers' inner support less attention. Therefore, how to improve social support for special education teacher also appears extremely urgent.

\section{The status quo of higher special education management work}

Current higher special education management mode dominates in the history of education in China, has had certain positive role. But with the higher special education management of the change of external environment and internal structure change, in the process of concrete of higher special education management gradually produced some disadvantages:

Education management concepts backward, security administration. From the current situation of higher special education management in our country, there is a legacy of the problem under the traditional planned economy system, both individual consciousness must be unconditional obedience collective consciousness, ignore the individual needs and development, it not only bad for school development, also does not favor the building democracy and harmonious society.

The higher special education management personnel lack of reasonable knowledge structure. At present, the higher special education management personnel are mostly from experience management, seldom learn education or special education, special education lack the necessary management theoretical basis. Combined with the daily job is busy, no more energy to systematically study related knowledge, understanding of special education management work can only rely on the steady accumulation of working experience at ordinary times slowly and form a kind of subjective understanding. The experience of management, not only seriously restricts the development of the school, but also not conducive to nations to achieve the goals of education modernization. 


\section{The problems of special education teachers' social support}

The sources of social support are rich enough. As a supporting resource, the source of social support is diverse, can be any one aspect of the social environment of the individual or all aspects. Due to the professional characteristics, teachers belong to a relatively isolated, relatively closed group, less interaction with the social contact. Special group in the face of special education teachers, in the education teaching needs to pay more time and energy, and the relatives and friends circle of contacts also shrinking, lead to many teachers have a problem, get more support and help. Besides, social perception is engaged in the special education teacher evaluation is generally lower, or that only third-rate teachers engaged in special education, it certainly adds to the special education teachers' sense of loss, inferiority complex or frustration, reduces the special education teachers' enthusiasm of social intercourse, make special education teachers' working and living space more narrow, the source of the support is relatively poor.

The content of the social support is relatively single. Social support is unusually rich; the content of the different social support provided by the social environment and social relations of content is different. Emily will social support is divided into six kinds, including: (a) with the help of the materials;(b) the behavior of the aid, such as the Shared physical labor; (c) close communicative behavior, such as listening, respect, care, understanding, etc.; (d) guidance, such as providing help, information and guidance; (e) feedback, such as providing feedback on individual behavior, thoughts and emotions; (f) positive social interaction, such as entertainment and relaxation of social intercourse activities. Usually, in providing social support, objective support due to provide visible, more attention to the practical help, subjective support relative advantage of less. Social support for special education teachers is mainly material support and information support, including the provision of financial help, material resources, and needed services, help to solve the problem of advice, guidance and evaluation. And provide emotional support for special education teachers and support is very limited, for special education teachers' social support that is single. In fact, individual subjective support for help relieve psychological stress reaction, mental tension, improve the social adaptation ability also has the vital role.

The use of social support degree is low. In addition to objective support and subjective support, social support may also include support exploitation degree, namely the individual in case of pressure and trouble utilization degree of support, when difficulties can actively use of social resources, the more beneficial to health of body and mind. However, special education teachers have a relatively low degree of social support utilization. On the one hand, is a special education teacher self defense the effect of psychological, social group teachers for higher social status, expectation, demand is higher, make special education teachers would not easily conceded defeat and helpless. On the other hand, influenced by Chinese traditional culture, special education teachers are reluctant to expose the psychological privacy, worry about suffering people around abnormal vision. Due to psychological concerns, in case of special education teachers more used to seek for the inner self regulation. So, many will not be able to make full use of social resources, even waste, make special education teachers with low social support utilization degree.

\section{The practice strategy of special education of the undergraduate course applied talents}

To build a applied talents training course system. Curriculum is the main carrier of implementation of the goal of talent cultivation, the reasonable curriculum is the basis of talent specifications accurate positioning, curriculum system is the main content of the talent training scheme. Special education of undergraduate course applied talents training is the most fundamental guarantee the rational and scientific professional and curriculum. Special education courses must be from the market of choose and employ persons of the subjects and the students' own development needs two aspects to consider, realize the curriculum integration and modular, guarantee the flexibility of personnel training and pertinence.

a) Open integration professional foundation course. Different types of special children psychology and physiology, education and rehabilitation methods in theory, such as generis, but in 
practice many contents are interlinked. Therefore, new course system still should highlight the concept of "integrated education", combining with the characteristics of different types of special children, strengthen professional internal integration and communication, make the student has a system of professional knowledge, enhance the adaptability of students. Such basic backbone courses, required courses such as principles of special education, special child psychology, special education, special children's basic medical, rehabilitation and training of special children, special children's measurement and evaluation, special children's early intervention, subject to a special school education, elective courses, such as special education, special education curriculum development, administration and regulations special children's case study, followed in the special education of social work, etc. In the curriculum, it is to consider the needs of different students, giving them the basis of sustainable learning.

b) Set professional direction module courses. Special education undergraduate course should be on the basis of the "comprehensive" outstanding "professional". According to the requirements of the student individuality development and social needs, set up different modules of elective courses, "modular" is a special education professional courses according to their nature and correlation are divided into different professional plate, highlight the directivity of training, let the students choose according to their interest in any one area of special education, specifically in major directions but good. According to the current in the field of special education needs, we offer professional module for special children rehabilitation training, and special crowd psychological counseling in both directions, courses in modules, the main direction of rehabilitation: overview of rehabilitation medicine, rehabilitation psychology and behavior change, life training (preschool or primary school), vocational training (secondary education stage), communication skill training; Special crowd psychological consultation direction: deviation (abnormal) behavior, behavior change techniques, children (adolescent) psychiatry, social skills training, consulting and practice principle. Let students choose one of the direction of further study, to achieve the ability to work in the corresponding special education. To form the "platform + module" curriculum structure system, the individuality of the learners, give students according to their own needs and goals for flexible learning opportunities.

c) The compression theory, outstanding practice class. Application-oriented undergraduate level of general education, mainly focus on practice, strengthening the application, especially in the practice training is the most can reflect practical feature of talent training. In our one body two wings ", on the basis of personnel training mode, we compress the special education professional undergraduate course of theory lessons, put theory in two and a half years to finish, the rest of the year and a half are mainly composed of trainee, practice and writing graduation thesis, including special schools teaching simulation, special education practice and social practice, professional and practical courses, such as experiment, practice and practice, cultivate students' interest in special education work and hobbies, to improve students' practice ability.

To reform the teaching methods and means. To reform the traditional teaching methods, adopting the advanced teaching method, stimulate students' autonomous learning ability, and improve the students' practical skills is the key to the special education to cultivate applied talents.

(a) Change the traditional pattern of "award - the", break the "force-feeding" teaching method, to encourage "heuristic", "divergence", "discussion-based" and "situational type" teaching method. By means of multimedia, a large number of cases improve the efficiency and effectiveness of classroom teaching. Teaching research and teaching reform in experimental activities, timely summarize the good teaching methods, teaching form and teaching method. Set up the students' knowledge, quality, ability, the coordinated development of education idea, the employment orientation is carried out based hierarchical teaching and learning, guide students always in view of the development of their own professional and specialized knowledge, arouse their curiosity, cultivate their ability of self learning, and explore new knowledge.

(b) Increase the practical teaching link, strengthen the practice ability and practice ability training. We have adopted a variety of strategy, make the practice teaching in the practical operation was strengthened. Is a professional education through lectures, academic report and other activities, 
show the prospect of professional knowledge, analysis of the use of professional knowledge, stimulate learners' intrinsic motivation. 2 it is to find and create conditions to develop a situational teaching, encourage students to deal with problems according to actual condition, raise their ability to solve problems. 3 it is according to different categories of courses, to the attention of the teachers to design of homework, such as students are required to collect related cases, education investigation, guides the student to utilize the knowledge into practice, cultivate the students' skills. Four is the organization to carry out various forms of curriculum practice, such as nation-wide publicity, antithetical couplet for disabled children and community, is a bridge between the theory and the practice, the role of the practice teaching quality education and bring out the best in each other. Five is to strengthen the training of practical skills; special children's activities mainly include sign language, design teaching AIDS, special education, sensory integration training skills, etc. Six is to use an open practice teaching, for students to special schools and rehabilitation institutions apprentice, the view of opportunity.

(c) To improve the exploitation degree of social support

Take the initiative to seek social support is also an effective means to cope with stress, differences between individuals to the use of social support. In front of the same social support, someone will take the initiative to seek and make full use of; There will be someone refused outside help, Someone doesn't have the consciousness of using social support or do not know how to use social support. And only active, make full use of social support, can truly benefit, eliminate the negative effects of occupational stress and negative life events. In general, support the exploitation degree is higher, the supporting resources. Special education teachers of social support, therefore, should have correct cognition, at the time of pressure and trouble, should keep an open mind, dispel the psychological concerns, active to the leadership, colleagues, friends, family and society to seek help, make full use of all possible social support to help you out of trouble, the positive interaction between formation and support network.

\section{Summary}

In short, higher special education management work is a complicated system engineering, which requires the higher special education managers are both generalist and specialist, can objectively understanding higher special education management work; Can require higher special education managers on the school's internal financial, personnel, teaching, decision-making aspects of scientific management at the same time, also can stand on the height of the country, brainstorming, formulate long-term development plan for the school.

\section{References}

[1] Guskey,T. R.Evaluating Professional Development. Journal of Women s Health. 2013.

[2] Ministry of Education,Training and Youth Affairs.Teachers for the 21st Century: Making the Difference. Journal of Women s Health. 2012.

[3] Kerka,S.Constructivism, workplace learning, and vocational education. (ERIC Document Reproduction Service No. ED407573). 2013.

[4] Lynton, R,Pareek, U.Training for Development. Journal of Women s Health. 2011.

[5] Patton.M.Q.Qualitative Research and Evaluation Methods. 2012

[6] U.S. Department of Education.Twenty-sixth annual report to Congress on the implementation of the Individuals with Disabilities Education Act. 2014 